\title{
Mindfulness of Ignorance
}

\author{
Edo Shonin $^{1} \cdot$ William Van Gordon ${ }^{1}$
}

Published online: 28 June 2015

(C) Springer Science+Business Media New York 2015

If a person is referred to as ignorant then according to the widely accepted meaning of this term, it is generally understood that they have a low level of knowledge or intelligence. However, within Buddhism and other Eastern contemplative traditions, the term ignorance assumes a somewhat different meaning. According to Buddhist thought, if a person is said to be ignorant, it normally means that they are ignorant as to the ultimate manner in which the self and phenomena exist. The practice of mindfulness of ignorance is concerned with cultivating awareness of the ignorant beliefs, behaviours, and perceptions that we have allowed to become established in the mind. By developing meditative awareness of our ignorant and unskillful ways, we create the correct conditions for transforming ignorance into wisdom. In this paper, we begin by briefly explicating a Buddhist interpretation of the term ignorance and explore whether it is possible for a person to be ignorant and intelligent at the same time. The second part of the paper then explicates the practice of mindfulness of ignorance which is conceptually stratified here into outer, inner, and hidden aspects. Emphasis is placed on applying the knowledge and understanding elicited by investigating the Buddhist construction of ignorance such that it informs, augments, and infuses our moment-to-moment practise of mindful awareness.

Edo Shonin

e.shonin@awaketowisdom.co.uk

1 Division of Psychology, Nottingham Trent University, Chaucer Building, Burton Street, Nottingham NG1 4BU, UK

\section{A Buddhist Interpretation of Ignorance}

In Western psychology, most models of the self are based on the assumption that there exists a definite "self" or "I" entity. However, contrary to this popular view, and despite the fact that most people derive reassurance from believing they inherently exist, the existence of a self or I that intrinsically exists is both a logical and scientific implausibility. Without exception, phenomena do not manifest as discrete standalone entities but manifest only in reliance upon innumerable causes and conditions. All phenomena-including human beings - are conditioned occurrences. They have inputs or causes and they have outputs or effects. If a single input is absent then a particular phenomenon does not arise, and neither does matter or situations that rely upon the phenomenon as a contributing cause. Therefore, animate and inanimate phenomena are interrelated to such an extent that it is not actually possible to delineate boundaries between them. Buddhism effectively asserts that in one thing, there exists everything. In other words and from the Buddhist perspective, if a single droplet of water in the atmosphere was "erased" from existence, the entire multiverse would cease to exist.

Consequently, the belief in an inherently existing self or I is considered in Buddhism to be a manifestation of ignorance because a self that exists independently and of its own accord is an untenable notion. Based on this interpretation and from the Buddhist perspective, ignorance basically means that a person is caught up in themselves and that they interact with the world through the lens of selfhood. They see the world in terms of a "me", a "mine", and an "I", and everything they think, say, and do is under the jurisdiction of the ego. 
Due to the fact that the ego can be very cunning and highly skilled at taking care of its own interests, then according to Buddhist thought, it is actually possible for a person to be intelligent and ignorant at the same time. This is a somewhat paradoxical notion that requires further explanation and is perhaps best understood by way of an example. In contemporary academia, there are some individuals who obtain their $\mathrm{PhD}$ and then continue to develop knowledge and expertise in what is arguably a very narrow and specialist area of knowledge. In many cases, such individuals play a role in shaping the terrain, rules, and boundaries of their given field of study. Put differently, there is a certain type of person working in academia that creates a bubble of knowledge, subject-specific terminology, and conventions, and then proceeds to live in it. In this bubble, they are the masters, the game developers, and rule keepers. Living in the bubble means that they can command respect from people that are not in the bubble (including from people that do not really have a clue what they are talking about but just presume it is tremendously complicated and important). However, when one looks at the crux of what is actually being proposed within a given scholarly theory, it can more often than not be reduced to some very simple themes and ideas. And for those instances where things cannot be explained in simple terms, then, in our experience, it often means that the bubble owners have got so caught up in the language and rules of their own self-created reality that they have begun to lose sense of how their research or sophistry relates to the real world.

In other words and in the example and scenario outlined above, the bubble dwellers are more interested in being (or appearing to be) intelligent rather than wise. Although their thinking and reasoning skills are effective and honed for use within their specific field of study, they may not be quite so adaptive in other remits of life. Consequently, when such individuals are presented with a completely new idea or way of working, they sometimes have difficulty in assimilating it. This is particularly the case when a bubble dweller meets a wise person that is imbued with the wisdom of meditative awareness.

There are lots of definitions of what is meant by the term "wisdom" in Buddhism, but we would briefly define it as the extent to which an individual accurately apprehends and understands both themselves and reality. A wise person knows every inch of their mind. They know why it exits, where it exists, and how it exists. They appreciate fully that they are both the observed mind as well as the mind that observes. Because they know their own mind, they also know every inch of everybody else's minds, and they are fully aware that all minds are interconnected. They are aware that their mind is without limitations, and they know that all other sentient beings also have the potential to have a mind without limitations. In short, their outlook is vast and unconditionally compassionate - everything is encompassed in it.

However, although the wise person has realised the full potential of their mind, they are in no way conceited or boastful about this. In fact, the wiser a person is, the more humble they are. Wise people do not have goals or agendas per se, and they place no importance on being recognised for their efforts or compassionate undertakings. Their main objective is to simply be, and from this state of simply being, profound tranquillity and lucidity arises that allows them to act in a way that is inconceivably skilful yet completely uncontrived.

An interesting observation concerning the Buddhist construal of wisdom is that intelligence is not a prerequisite for being wise. There are numerous different types and interpretations of intelligence, but here we are using the term according to its popular (and Oxford English Dictionary) definition of the ability to acquire and apply knowledge and skills. Thus, although there is a strong probability that a wise person will be intelligent according to the conventional meaning of this term, there is also the possibility that they will not be. Intelligence is a tool that wise people can cultivate and make use of if they wish to, but wise people understand that intelligence needs to be developed and handled carefully. This is because in the absence of wisdom, intelligence can significantly limit the mind. It can become an obstacle to enlightenment and therefore an obstacle to the ongoing development of a dynamic and fluid wisdom.

Upon meeting a wise person, the normal reaction of the bubble dweller that we referred to earlier is to feel threatened and to reject the wise person as well as their ideas. However, because the wise person is just simply being and is not trying to be somebody in particular, their wisdom is very powerful, unshakeable, incredibly piercing, and absolutely logical. By piercing, we don't mean that they have a smart retort to everything, we just mean that their basic presence - even when they aren't saying anything — is very penetrating. The wise person's wisdom gives the intelligent person's ignorance a sudden and massive shake. The intelligent-ignorant person (or, if you prefer, the ignorantintelligent person) starts to feel threatened because they know that if they remain in the presence of the wise person, they will be forced to accept that they have created and are living in a very small bubble. They know that the wise person's wisdom will burst their bubble, and they will no longer have any ground to stand on.

Please do not misunderstand what we are saying here-we are not saying that contemporary academics are actually very ignorant. Indeed, we are fortunate to know some very wise academics that are also incredibly intelligent. We used the example of a certain type of individual working in academia simply because it is reasonably easy to relate to. However, in 
truth, "bubble dwellers" exist in all walks of life_-including within the mindfulness and meditation practice and teaching community.

\section{Mindfulness of Ignorance: Outer Aspect}

We practise mindfulness of ignorance in order to transfer ourselves from the domain of ignorance and dwelling in a bubble, to the state of wisdom, open mindedness, and clarity of perception. As referred to above and for didactic purposes, mindfulness of ignorance can be divided into outer, inner, and hidden aspects. The outer aspect of the practice of mindfulness of ignorance involves applying knowledge and understanding concerning what constitutes ignorance (i.e., as explicated in the first part of this paper, and in the traditional meditational literature more generally) to the moment-to-moment practise of mindful awareness. Some (so called) meditation teachers and practitioners are very good at filling up their minds with theories, knowledge, and information, but they are less proficient at putting the theory into practice. In other words, it is all very well coming to a conceptual understanding of the fact that we and the world around us are "empty" of intrinsic existence, but unless we can make that understanding work for us during meditation, it is of limited value.

In the first instance, the way to integrate the practice of mindfulness of ignorance into our day-to-day mindfulness training is to simply remember that the various physical and psychological phenomena that we observe and encounter during meditation exist in a manner that is different to how they appear. We breathe in observing and experiencing the full texture of the in-breath, but we remember that the in-breath exists only as a dependant origination. We breathe out observing and experiencing the full texture of the out-breath, but we remember that the out-breath is empty of inherent existence. When we walk, talk, sit, work, eat, drink, listen, or lie down, we do so with full awareness to the task at hand. However, we introduce a new dimension to mindfulness practice by also remembering that both we and the object or objects of our meditative awareness are devoid of intrinsic existence. We remember that our perception of phenomena is erroneous and is tainted by ignorance.

The idea of remembering that our interpretation of reality is subject to ignorance is not to belittle ourselves or in any way beat ourselves up. Rather, it is to help us grow in confidence as mindfulness practitioners and as human beings more generally. We grow in confidence because we make allowance for the fact that our choices may be subject to an imperfect understanding and perception of a given situation. Most people do not take the time to evaluate their choices in this mannerthey are impelled by their ego and attachments, and they dive straight in. However, being aware of our and others' ignorance means that we can remain dynamic, flexible, and open to other ways of doing things. By being certain that there can never be complete certainty in terms of how we interpret the world around us, our perception of reality becomes more closely aligned with the true and absolute mode in which phenomena abide. We grow in confidence as we begin to understand and work with the underlying fabric of the present moment.

\section{Mindfulness of Ignorance: Inner Aspect}

Whilst practising the outer aspect of mindfulness of ignorance, our practice was still very much contrived. We were focussing a part of our concentration on keeping in mind the fact that ignorance was interfering with our perception, and we employed mindfulness to regulate this concentration and refocus the mind each time meditative concentration was lost. In other words, we were remembering the truth, rather than seeing and realising it directly.

As part of the inner aspect of the practice of mindfulness of ignorance, things are much less contrived. By "loading" our practice of mindful awareness in the manner outlined above, it becomes much more spiritually potent. Consequently, with repeated practise and coupled with the insight derived from other forms of meditation, we eventually find ourselves in a situation where we do not have to "remember" to be aware of ignorance any more. Rather, we begin to see the true nature of ignorance. We begin to see that in actual fact, ignorance and wisdom are exactly the same thing. The only factor that differentiates these two states is our own perception.

Realising that wisdom and ignorance are one and the same thing is what we meant when we referred at the beginning of this paper to the process of transforming ignorance into wisdom. However, in truth, nothing is actually transformed, and the present moment remains just as it always was. The only difference is that now we perceive it in a completely different manner. We started off by cultivating mindfulness of ignorance, but in truth and all along, we were also cultivating mindfulness of wisdom.

\section{Mindfulness of Ignorance: Hidden Aspect}

By correctly comprehending the inner aspect of mindfulness of ignorance, we begin to see reality in its absolute form. However, at this point, there is still a tendency towards believing that we are "practising" something in order to get somewhere. In other words, there is still a subtle attachment to the notion of us being a mindfulness or meditation practitioner and of ignorance being something we should endeavour to transcend. For this reason, the direct perceiving of the ultimate nature of reality tends to be something that is limited to occasional (albeit spiritually potent) glimpses. 
The way to overcome this subtle form of attachment is to realise and intuit that for as long as we see ourselves as a "mindfulness practitioner", we are still functioning in the domain of ignorance. Mindfulness requires the presence of an object or objects that we can use as focus points for placing awareness. Examples of such meditative objects include the breath, body, feelings, thoughts, present moment, and ignorance (i.e., as discussed above). However, for as long as we see objects as objects and try to be mindful of them, then we are still cultivating ignorance.

We have referred to this aspect of mindfulness of ignorance as being "hidden" not just because its meaning is not immediately apparent but because it needs to be interpreted with care. In effect, what we are saying is that mindfulness practice — of any form - helps to introduce "breathing space" into the mind. It allows thoughts, feelings, and objects of awareness to be observed, "cradled", and subsequently investigated. However, although mindfulness is a prerequisite for advancing along the path of meditation, it is still a practice that is subject to, and leads to the propagation of, ignorance.

The hidden aspect of mindfulness of ignorance is concerned with completely relinquishing the idea that there is something to practise or that there exist such things as ignorance or wisdom. We are not practising something in order to get somewhere because there is no-thing to do and no-where to be. We simply are. In effect, this aspect of the practice is concerned with understanding that even the most ignorant of people are, at all times, breathing, eating, and walking through emptiness. Liberation is literally in the palms of their hands. There is no physical abode called "samsara" (i.e., the realm of suffering and cyclic existence) and there is no physical abode called "nirvana". In other words, beings subject to ignorance and suffering are, for all intents and purposes, living in nirvana. They just do not realise it. This predicament adds a certain sense of irony to the suffering that the Buddha asserted was a mark of existence, and the fact that it can be permanently circumvented by a simple change of perception makes samsaric misery all the more cruel and nonsensical.

\section{A Close Truth}

Like the repose that follows, When waking from a nightmare.

Like the reprieve of an isolated General, Who recognises the encroaching soldiers as his own troops.

Like the relief that arises, When realising that the snake, was, all along, just a piece of old rope.

Like the rapture of the despairing treasure hunter, Who returns to find the riches buried beneath his own home.

Oh self who has enslaved me for so long,

Now I have shed the shackles of ignorance,

And entered the non-returning blissful abode.

Acknowledgments Some parts of this article are much expanded upon and/or adapted themes and contemplations that first appeared on the authors' meditation blog (www.edoshonin.com).

\section{Compliance with Ethical Standards}

Conflict of Interest The authors declare that they have no competing interests. 